\title{
Application of Big Data in Comprehensive Emergency Management Platform in China
}

\author{
Pengcheng $\mathrm{Lu}^{1,2, \mathrm{a}}$ and Naiping Zhang ${ }^{1,2, \mathrm{~b}^{*}}$ \\ ${ }^{1}$ Management School, Wuhan University of Technology, Wuhan 430070, China \\ ${ }^{2}$ China Research Center for Emergency Management, Wuhan University of Technology, Wuhan \\ 430070, China \\ a1942634130@qq.com, b541365020@qq.com \\ *The corresponding author
}

Keywords: Emergency management; Big data; Emergency; Platform architecture

\begin{abstract}
Based on big data technology and thinking, using comprehensive emergency platform has become an inevitable choice to improve emergency management level, under the background of big data. This paper discusses the concept and the trend of big data, analyzes the relations between big data and emergency platform, in view of the current lack of emergency platform, take provincial emergency platform for example, design comprehensive emergency platform overall architecture based on big data, to solve the data collection, transmission, storage, analysis, display. And study how to use the emergency platform to prepare for prevention, monitoring and early warning, emergency disposal, return to work with big data technology and thinking, for improving the capacity of emergency management.
\end{abstract}

\section{Introduction}

In recent years, the public emergency management in China and the world has showed a trend of normalized management. The occurrence of all kinds of emergencies cause a large number of casualties and economic losses, serious impact on social harmony in our country, a serious threat to people's life and property safety. Visible, the Chinese government's situation of emergency response is very serious. How to build and use comprehensive emergency management platform to deal with public emergencies, realize the unified command, responsive, complete functions, efficiency of emergency management system, improve the emergency management ability are getting attention from the national level. At present, the emergency departments at all levels have their own emergency system, which greatly improve the emergency management ability. However, due to the rapid development of modern information technology, different areas data resources from various business units of emergency system, various bureaus, different business areas of various also shows the tendency of explosive growth. Use the traditional way to effective management and sharing the data.

Recently, big data technology brings great change to collection, transmission, storage, mining and show of large scale data. Under the background of big data, big data is not only a technical change, but also a thinking change. In the future, more management, supervision and service decisions will be based on the results of data analysis. Big data will be the next generation of cutting-edge innovation, and has been into the various fields today, which is closely related to our real life [1]. Visible, using big data technology and thinking to the construction of comprehensive emergency platform, improve the emergency management ability has become an inevitable trend.

\section{The Concept and Relationship with the Emergency Platform of Big Data}

The Concept. Big data is new a technology which can effectively solve the problem of huge amounts of data collection, storage and display [2]. Mayer-Schonberg pointed out big data is the source of people getting a new cognition, creating new value; big data also the method of changing market, organizations, and the relationship between government and citizens [3]. Big data is not only the 
technology which solve the problem of collection, analyses, storage and display of big data, but also a thinking and method to solve problems with big data analysis technology. Compared with the traditional technique of data, big data technology has the characteristics of $4 \mathrm{~V}$, which are Volume, Variety, Value and Velocity [4].

In recent years, many big data processing systems has been developed, which have its own characteristics. In general, there is three development trends. Customization of big data processing engine. Big data ecosystem is formed. Interaction and real-time of data calculation are needed [5, 6].

The ultimate goal of the analysis and processing is to use the understanding of the data supporting people make reasonable decisions in all kinds of applications. During this process depth learning, knowledge computing, social computing and visualization play a complementary role [7]. Dig data analysis adopts the method of whole sample and multi-party data analysis to increase the depth of data mining and focus on the correlation of the problem. In general, large data analysis depth mining data value, improves the data learning accuracy, and promotes social cognition

The Relationship between Big Data and the Emergency Platform. Government data contains enormous economic and social value. With the increasing demand to get and use of government data, how to manage, store, utilize and disclose government data has become an urgent problem for government. Many countries attach great importance to applications of big data in public management and emergency management. In 2012, the Obama administration announced the investment 200 million US dollars to develop big data research projects involving multiple federal departments and agencies; Japan is officially announced in June 2013, "creating the most cutting-edge IT national declaration" [8]. China's Guangdong Province has taken the lead in big data technology for government data management. We can see that "Big Data" is not just a new technology, but also important factor to improve the level of state governance.

At present the relevant emergency departments and special emergency projects have their own information systems. These systems are mainly faced with internal business services, resulting in service narrow, and difficulty in direct interaction between the various departments. Although there are some integrated emergency platform, but the existing platform structure is simple, and lack of effective organization and system planning. So it is difficult to deal with big data.

In emergencies, data collection, processing, and use still require complex and even traditional manual methods of conversion and processing in order to provide decision-makers to use, often due to time constraints, these data are often lack of integrity, accuracy and real-time. Therefore, we must use large data technology to build an emergency response platform to achieve cross-sectorial integration of emergency data.

\section{Provincial Emergency Platform Architecture}

The existing emergency system can be reconstructed to comprehensive emergency management platform with big data. Government, enterprises, and various social forces can rely on the platform for emergency management. This will greatly improve the efficiency of data exchange, emergency response and reconstruction. This paper will design the provincial emergency platform architecture, which is very representative in the emergency platform.

Requirements of Provincial Emergency Platform. Provincial emergency platform plays a role in connecting the upper and lower in the national emergency platform system. It achieve interoperability down to the city and county level emergency platform, integrate departmental emergency platform and special emergency platform, complete the data submission to China 's State Council emergency platform [9]. Design of provincial emergency platform should be based on the actual situation in the provinces. The platform should meet the needs of emergency preparedness for the prevention, monitoring and early warning, and post-disaster reconstruction. Provincial emergency platform claim as follows.

Integrate various emergency data resources for a rapid response, full-featured, unified command the emergency platform. 
Achieve the rapid collection and transmission, a high degree of integration, sharing, and depth mining of emergency information.

In the field of risk prediction, dynamic prediction is made on the basis of historical data and real-time monitoring data combined with actual situation. In the field of emergency response, the platform could provide help for decision-making of emergency rescue, with analytical models and multi-party data.

Structure of the Provincial Emergency Platform. To meet the requirements, the provincial emergency platform architecture based on large data is logically divided into four levels: Hardware layer, data collection layer, data storage layer, data analysis layer and display layer. The structure shown in Fig. 1.

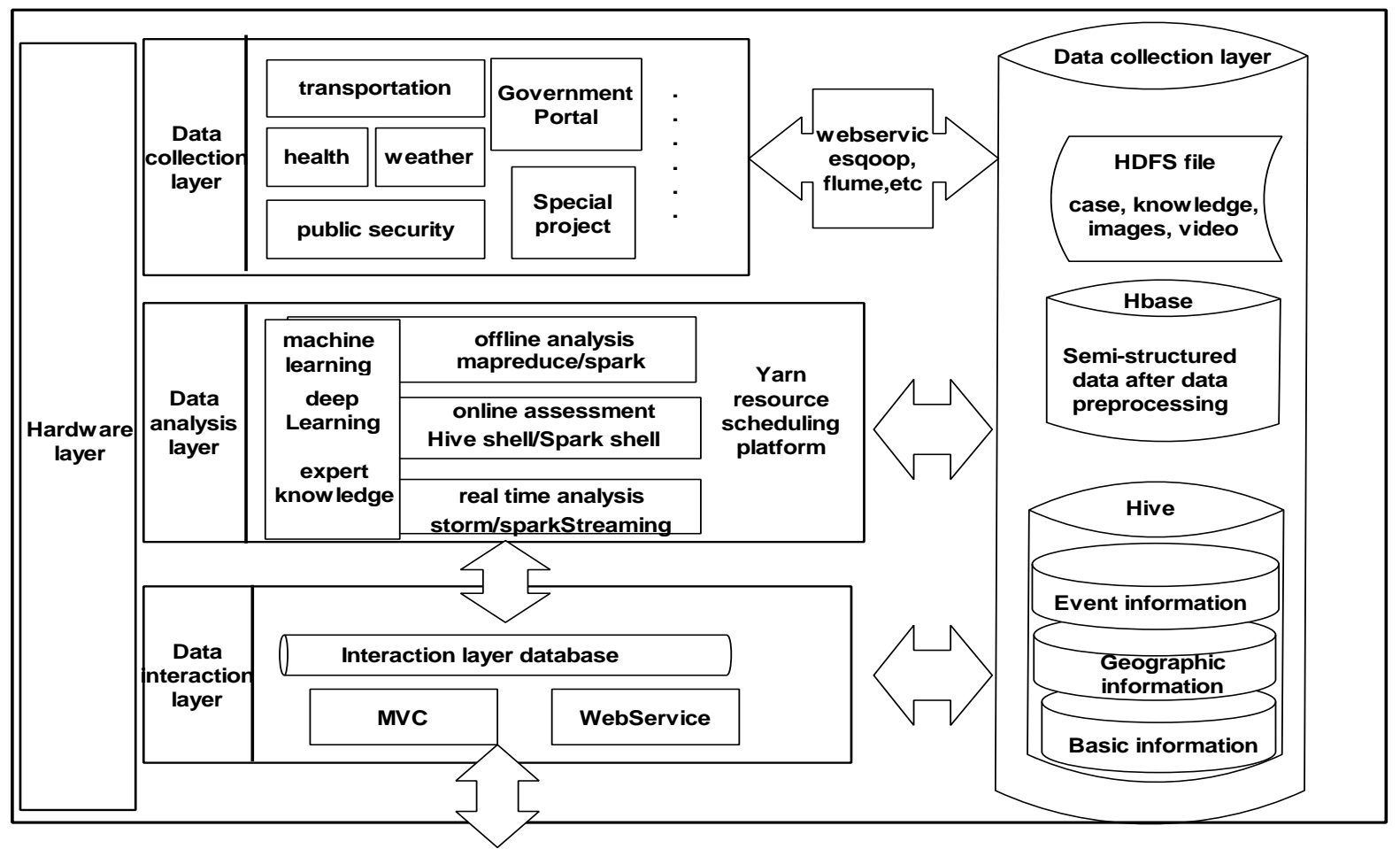

Figure 1. Structure of provincial emergency platform based on big data

Hardware Layer. In the context of big data, the data collection, transmission, storage, calculation of the provincial emergency platform presents new challenges. As a result of a wide range of data sources, involving cross-system, cross-network transmission, the platform needs intelligent sensing devices, sensors, high-speed broadband network security systems and emergency communications systems. To meet the mass storage and large-scale computing needs, the entire emergency response platform use distributed architecture, which requires a large number of high-capacity, high performance, high reliability, cost-effective server.

Data Collection Layer. The data collection layer mainly realizes the function of acquiring or receiving the data from emergency departments, government portals, special emergency management projects, city and county emergency management platform, and the national emergency management platform and storing it in the data resource layer. As the platform of the complex data sources, the information system architecture, programming technology is difficult to unity. Each data source information system needs to use the Web Service technology to provide the external call connection, in order to information collection. The platform also relies on data migration tools to easily migrate data from traditional relational databases to a data resource layer using large data storage technologies. For some data that needs to be collected in real time or periodically, Flume can be used

Data Storage Layer. In the big data environment, the provincial emergency platform needs to deal with the diverse type of data, and a huge amount of data. Large data in the data resource level can be 
stored and managed using the Hadoop Distributed File System (HDFS), which is currently the most widely used. Data can be divided into structured data, semi-structured data, unstructured data. For a wide range of data need to be reasonably handled, stored to facilitate data management and other levels of data interaction. The platform needs to manage the data rationally, in order to facilitate interaction with other layer. Unstructured data not need to frequently update can be stored by HDFS file categorized according to a certain format, such as contingency plans, cases, pictures, etc. Structured data can be stored by Hive, which is large data warehouse tool base on Hadoop, such as basic information, geographic information and so on. HBase, a kind of NoSQL database based on Hadoop, can be used to store Semi-structured data, to speed up the data query call speed. The use of big data, can improve collaboration capabilities, and avoid the formation of information islands.

Data Analysis Layer. The data analysis layer mainly realizes the function that analyzes and mine the data of warning, response, coordination, disposal, and provides decision support for the emergency managers. The platform could obtain the required data from the data resource layer according to the actual demand. As to complex problems, use machine learning, in-depth study, combined with expert knowledge to analyze the data. Then the results will be stored in the display layer database for query call. Data, which need periodic or interactive analysis and processing, can be offline processed with Hadoop's computational framework or a memory-based Spark framework. Due to the suddenness and uncertainty of the emergent events and the uncertainty of the data and methods to be analyzed, Hive's CLI or spark shell approach is required to implement flexible offline processing. If real real-time analysis and processing is needed, real-time or micro-batch flow calculation framework could be used, such as Storm, Spark Streaming, etc.

Data Display Layer. The data interaction layer mainly realizes the release and interaction of emergency information. The interaction of emergency information has three meanings: Emergency information can be published through the government portal, government microblogging, mobile phone short message and other methods; the resulting data needs to be presented to the decision maker through a visualization tool that facilitates decision making and perception of the data; provide external data call interface to facilitate the transfer of data to other projects. MVC (Model View Controller) framework can be used for data display and information dissemination. Data call interface for external projects can use Web Service technology.

\section{The Use of Emergency Response Platform with Big Data}

The application of big data in emergency management is embodied in large data technology and large data thinking. Large data technologies include technologies such as data warehouses, data marts, and data visualization as described above. While big data thinking is based on dig data platform data found the problem from the massive, think about the problem with the whole sample, form a fuzzy, relevant and holistic approach [10]. Mutual integration and support of big data technology and big data thinking of can really form large data applications. Very often, as long as we change the traditional way of thinking, change the workflow with large data thinking, analysis of existing data, big data applications could form. Crisis life cycle is divided into four stages: brewing period, outbreak period, diffusion phase, and settlement period, which includes prevention preparation, monitoring and early warning, rescue and recovery and summary of emergency management work. Big data in emergency management applications will penetrate into all aspects, but because of the variety of emergency events, not all emergency management work will involve large data integrity applications. This paper discusses the application of big data thinking in emergency management, based on the provincial emergency platform architecture. Using of the basic framework with big data thinking shown in Fig. 2.

Latent phase of the emergency incident, emergency events is still in a latent state, platform maintenance and management preparation is required. Platform maintenance, including hardware maintenance, software maintenance and data maintenance for data acquisition, transmission, storage, processes. Data maintenance refers to the collection, sorting and storage of data for emergency 
management work. This involves not only the collection of new data but also the secondary processing of the original data in order to maximize the value of the data. Management preparation refers to the management of staffing and skills upgrading. Big data requirements sufficient clerk with large data technology and large data thinking, so as to better maintenance platform operation, and enhance emergency management ability.
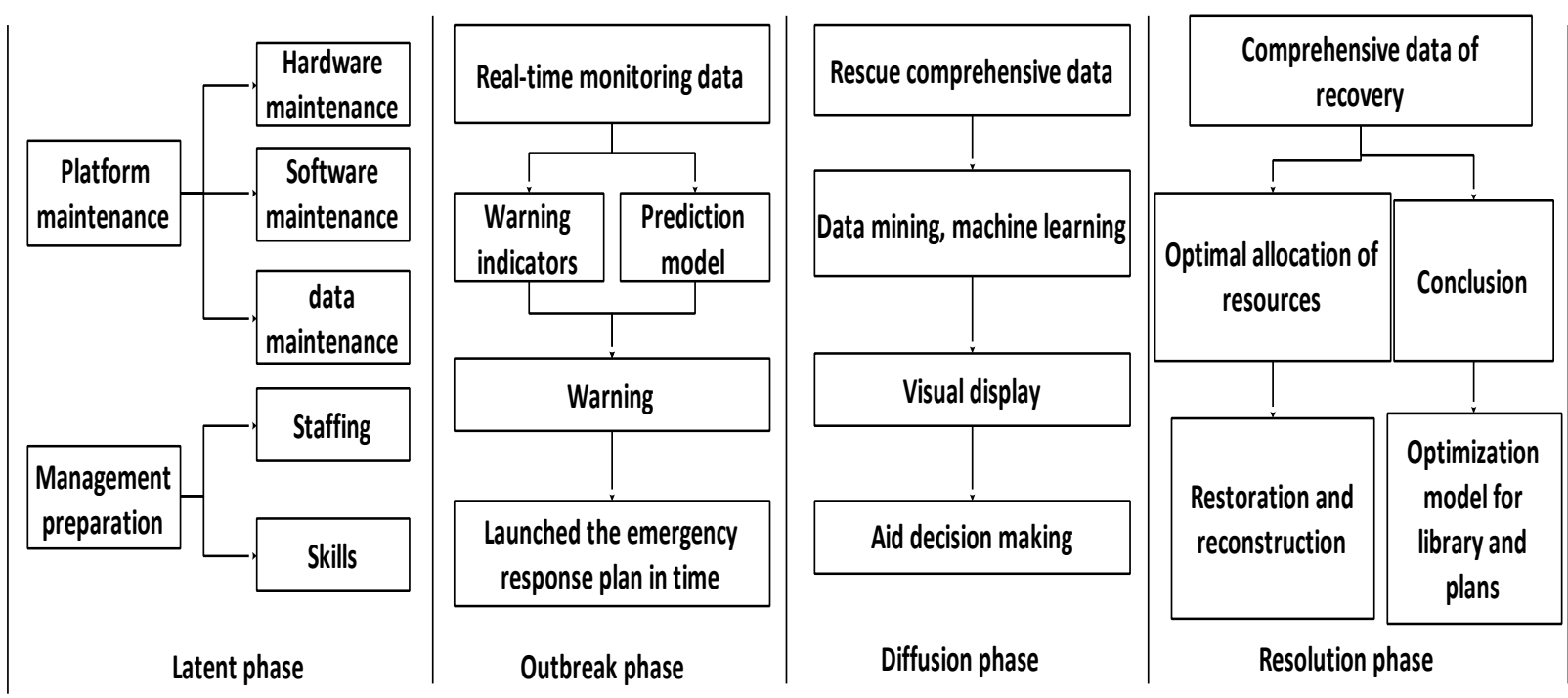

Figure 2 Using of the basic framework with big data thinking

The outbreak of emergencies refers to the accumulation of all kinds of inducement factors, and reaches a definite degree and then erupts. In this phase should use big data technology to do a good job of monitoring and early warning. Forecast is the core function of the big data. The use of large data technology for early warning of emergencies can prevent the occurrence of emergencies, to reduce the losses caused by unexpected events [11]. To do early warning, we must excavate historical data, design a reasonable real-time warning indicators system. If the monitored data exceeds the normal range set, it will issue an early warning message, and in the appropriate time to start the corresponding emergency plan.

Emergency diffusion phase means that emergent events have occurred and caused losses. During this period, we can use the emergency platform to analyze and analyze the multi-party data, rationally utilize the technology of data mining and machine learning to allocate the resources of emergency, such as manpower, material resources and financial resources, carry out crisis rescue, control the scope and degree of crisis, to reduce the impact of public crisis or sub-public crisis. At the same time should also open reasonable information to public, business, professional researchers, forming a wide range of social collaborative rescue.

The emergency resolution phase is the final stage of the incident. During this period, we should do a good job in post-disaster reconstruction. At the same time, we should conduct a positive self-analysis and review; summarize the shortcomings of various aspects of the emergency platform. And analyze the causes of public crisis, to find the nature of the public crisis, re-integration of data, contingency plans, and analysis of decision-making model.

Due to the different tasks of emergency management, the causes, characteristics and damage degree of different types of emergencies in different provinces are not the same. When dealing with different emergencies, the emergency response is different. Such as the occurrence of a tsunami is very sudden, short duration, but the damage is very large, recovery time is long, it is difficult to do effective "things in response". This situation should focus on how to use large data to do a good job in prevention, early warning and post-disaster recovery work. Therefore, use of large data platform of 
the provinces should be combined with local conditions, and the different characteristics of emergency events.

\section{Conclusions}

Emergency platform is an important part, the important tools and basic guarantee of the national emergency management system. After analyzing the concept and development trend of large data, this paper discusses the application of big data in emergency platform for the according to the shortcomings of current emergency management platform. After analyzing the concept and development trend of large data, this paper points out the shortcomings of current emergency management platform, and discusses the application of large data in comprehensive emergency management platform. Taking the provincial emergency platform as an example, this paper puts forward the overall architecture of the emergency platform based on large data, and studies how to use the emergency comprehensive platform to deal how to use the emergency comprehensive platform to deal with emergent events with large data thinking. To apply big data to the emergency platform, we need to consider the following three aspects.

Strengthen the construction of emergency platform data system. The emergency platform must have supporting hardware and software facilities to deal with massive data collection, transmission, storage, processing challenges.

Enhance the skills of managing large data sets. In order to excavate the value of big data, the platform needs to be equipped with enough professional big data personnel. The Government should adopt appropriate policies to cultivate big data talents, and actively guide large data talent work in the field of emergency management.

Change into the way of big data thinking. In big data thinking mode, we should emancipate the mind to enhance emergency management capabilities, combining with the actual situation of emergency management.

\section{References}

[1] H. Wang, Z.S. Xu, H. Fujita and S.S. Liu: Towards felicitous decision making: an overview on challenges and trends of big data. Information Sciences, Vols. 367-368 (2016), p. 747.

[2] M. Chen, S.W. Mao and Y.H. Liu: Big data: a survey, Mobile Networks and Applications, Vol.19 (2014) 2, p.171.

[3] V. Mayer-Schonberger and K. Cukier: Big Data: A Revolution That Will Transform How We Live, Work, and Think (Houghton Mifflin Harcourt, America 2013), p.20.

[4] Gandomi and M. Haider: Beyond the hype: Big data concepts, methods, and analytics. International Journal of Information Management, Vol. 35(2015) No.2, p.137.

[5] Yaqoob, I.A.T. Hashem,A. Gani, et al: Big data: From beginning to future, International Journal of Information Management, Vol. 36(2016) No.6, p.1231.

[6] X.L. Li and H.G. Gong: A survey on big data systems, Scientia Sinica Informationis, Vol. 45(2015) No.1, p. 1.(In Chinese)

[7] X.Q. Cheng, X.L. Jin, Y.Z Wang, et al: Survey on Big Data System and Analytic Technology, Journal of Software. Vol. 25(2014) No.9, p.1889.(In Chinese)

[8] G.H. Kim, S. Trimi and J.H: Chung. Big-data applications in the government sector, Communications of the ACM, Vol. 57(2014) No.3, p.78.(In Chinese)

[9] D.G. Kong, Research on Construction of Emergence Platform in Gansu Province (Ph.D., Lanzhou University, China 2008), p.30.(In Chinese) 
[10]T. Ma and Q.F. Mao: The Application of Big-Data Approach in Emergency Management, Chinese Public Administration, Vol. 357(2015) No.3, p.136.(In Chinese)

[11]W. Fan and A. Bifet: Mining big data: current status, and forecast to the future, Acm Sigkdd Explorations Newsletter, Vol. 14(2013) No.2, p.1. 